\title{
Evaluation of serum levels of neurotrophin 4 and brain-derived nerve growth factor in uremic pruritus patients
}

This article was published in the following Dove Medical Press journal: Clinical, Cosmetic and Investigational Dermatology

\author{
Neveen E Sorour ${ }^{1}$ \\ Fatma M Elesawy' \\ Hala A Tabl ${ }^{2}$ \\ Mohammed E Ibrahim ${ }^{3}$ \\ Essam M Akl' \\ 'Department of Dermatology, \\ Venereology and Andrology, Faculty \\ of Medicine, Benha University, Benha, \\ Egypt; ${ }^{2}$ Department of Microbiology \\ and Immunology, Faculty of Medicine, \\ Benha University, Benha, Egypt; \\ ${ }^{3}$ Department of Internal Medicine, \\ Faculty of Medicine, Benha University, \\ Benha, Egypt
}

Background: Pruritus is a common symptom in end-stage renal failure. Many patients suffer from this severe distressing symptom. Although several factors have been postulated to explain uremic pruritus, there is not any conclusive evidence for one of these factors.

Objectives: We aimed to evaluate serum levels of brain-derived nerve growth factor (BDNF), neurotrophin-4 (NT-4), serum calcium, phosphors and parathyroid hormone in uremic patients with pruritus and without pruritus compared to control subjects.

Methods: One hundred twenty patients suffering from renal failure and 60 healthy subjects were included in the study. Serum BDNF and NT4 levels were determined by ELISA. The serum calcium, phosphorus, parathyroid hormone and hemoglobin were also evaluated.

Results: Serum BDNF was significantly higher in uremic patients with pruritus $(P=0.0026)$ and uremic patients without pruritus ( $P=0.0294)$ than control subjects. In addition, NT-4 levels were significantly elevated in uremic patients with pruritus $(P<0.0001)$ and uremic patients without pruritus than control subjects $(P=0.0016)$. There was no significant difference of serum level of BDNF between uremic patients with pruritus and uremic patients without pruritus $(P=0.1215)$. However, serum NT-4 was higher in uremic patients with pruritus vs nonpruritic uremic patients with a significant difference $(P=0.0026)$. There was a positive significant correlation between serum level of NT-4 and severity of pruritus $(P=0.024)$.

Conclusion: The present study shows that NT-4 level is increased in the serum of uremic patients with pruritus and there was a significant correlation between NT-4 and severity of pruritus suggesting that NT-4 may have a role in uremic pruritus.

Keywords: brain-derived neurotrophic factor, neurotrophin-4, uremic pruritus

\section{Introduction}

Uremic pruritus is a common problem seen in hemodialysis patients with prevalence ranging from $51 \%$ to $81 \%,{ }^{1,2}$ it has been associated with a negative impact on patients' quality of life. ${ }^{3}$

The pathophysiological process of pruritus associated with chronic kidney disease remains not fully elicited; ${ }^{4}$ however, several theories have been suggested such as systemic inflammatory process, parathyroid hormone elevation, calcium and phosphorus disequilibrium, an imbalance in opiate receptors agonist, and a neuropathic process. ${ }^{5}$ Neurotrophins are a group of neurological mediators that have a role in pruritic skin diseases. ${ }^{6,7}$

\section{Aim of the study}

The aim of the present work was to evaluate the serum levels of neurotrophin-4 (NT-4), brain-derived nerve growth factor (BDNF), serum calcium, phosphors
Correspondence: Essam M Akl

Department of Dermatology,

Venereology and Andrology, Faculty of Medicine, Benha University, Farid Nada Street, Benha, I35II, Egypt

Tel +20 I005645255

Email esamakl@hotmail.com 
and parathyroid hormone in uremic patients with pruritus under regular hemodialysis who are complaining of chronic pruritus.

\section{Patients and methods}

The present study is cross-sectional case-control comparative study that was carried out between October 2017 and March 2018. This study was conducted in Renal Dialysis Unit, Dermatology and Microbiology Departments, Benha University Hospitals, Benha, Egypt, after approval by Ethics Committee for Human Research, Faculty of Medicine, Benha University, Egypt and was conducted in accordance with the Declaration of Helsinki. All the participants had given a written informed consent before enrollment in the current study. Study population: this study enrolled 180 participants older than 18 years of age who were divided into three equal groups - Group A included 60 patients under regular hemodialysis complaining of chronic pruritus, Group B included 60 patients under regular hemodialysis not complaining of chronic pruritus, while Group C included 60 normal individuals, who were both sex and age matched and not complaining from either any pruritic or systemic diseases.

Uremic patients under regular hemodialysis and complaining of chronic itching that not improved under regular hemodialysis were included in this study. Both uremic patients with pruritus and without pruritus were under regular hemodialysis (three sessions per week), for more than 6 months duration. Subjects with either chronic hematological disease, hepatic, pregnant, endocrinal disorders, other itchy skin disease, psychiatric disorder or under chemotherapy treatment were not included in this study.

A complete medical history was taken from patients including cause of renal failure, duration of hemodialysis, pruritus intensity, effect of hemodialysis on pruritus and previous treatment of pruritus.

An examination of the patients was done to exclude any primary itchy skin lesions and determine pruritus severity. Pruritus severity was determined using 5-D itch scale (5D-IS). ${ }^{8-10} 5 \mathrm{D}$-IS is multidimensional questionnaire containing five dimensions (degree, duration, direction, disability and distribution) and can assess impact of itch on quality of life. The duration, degree and direction domains each included one item, while the disability domain had four items. The first four domains are measured on a 5-point Likert scale. The distribution domain included 16 potential locations of itch and sum of 2 points equals 1 point. ${ }^{8}$

Patients with $5 \mathrm{D}<15$ score were excluded from this study, as the pruritus severity was mild and may be to other causes than uremia. The 5D-IS was measured before the beginning of the dialysis session on the same day of blood sampling.
Patients were classified according to the severity of pruritus into three groups: moderate group (5D score from 10 to 15 ), severe group (5D score $>15-25$ ) and very severe group (5D score $>25)$.

\section{Laboratory investigations}

Complete blood picture, ESR, serum bilirubin, calcium, phosphorus, blood creatinine and parathyroid hormone measuring were done prior to hemodialysis session.

Ten-milliliter blood samples of patients (before hemodialysis session) and controls were withdrawn from an antecubital vein into the anticoagulant-free biochemical tubes in the morning after regular overnight sleep. Blood samples were centrifuged at 4,000 rpm for 5 minutes after complete clotting. The obtained serum was stored at $-80^{\circ} \mathrm{C}$ until assayed. Serum levels of BDNF and NT-4 were measured by ELISA by available kits (Aviscera-Bioscience, Santa Clara, CA, USA, and DuoSet, R\&D Systems, Minneapolis, MN, USA, respectively).

\section{Statistical analyses}

The independent $t$-test was used to compare the numerical data of normally distributed variables, while categorical variables differences were analyzed with chi-squared test. Spearman correlation was used to examine correlations. If the $P$-values were $\leq 0.05$, it was considered significant. The statistical analysis was achieved using the SPPS $^{\circledR}$ program for Microsoft Window $7^{\circledR}$.

\section{Results}

This study included 180 participants. Their demographic data are summarized in Table 1 . There was no significant differences regarding age, sex or BMI $(P=0.1448,0.935$, 0.082 , respectively). In addition, there was no significant differences regarding serum calcium or phosphors level ( $P=0.261,0.409$, respectively). Control participants had a higher hemoglobin level than uremic patients with a significant difference $(P<0.0001)$. Results of this study showed significant elevations of parathyroid hormone $(P<0.0001)$, urea $(P<0.0001)$, creatinine $(P<0.0001)$, NT-4 $((P<0.0001)$ and $\operatorname{BDNF}(P=0.0029)$ in uremic patients than control (Table 1$)$.

Comparing uremic patients with pruritus vs without pruritus, there were no significant differences found regarding age, sex, BMI, hemoglobin, serum parathyroid hormone, calcium, phosphorus, urea, creatinine or duration of hemodialysis $(P=0.999,0.855,0.83,0.33,0.905,0.816,0.882$, 0.4933, 0.0967, 0.266, respectively, Table 2). Serum NT-4 was higher in uremic patient with pruritus vs nonpruritic uremic patients with a significant difference $(P=0.0026)$. 
Serum BDNF was higher in uremic patients with pruritus vs nonpruritic uremic patients; however, it was nonsignificant $(P=0.1215)$ (Table 2).

According to uremic patients with pruritus 5D score, the moderate group included 18 patients, severe group included 19 patients while very severe group included 23 patients with
$5 \mathrm{D}$ score $>25$. There was a significant difference regarding NT-4 serum level between the three subgroups $(P=0.0458)$ and there was no significant difference regarding BDNF $(P=0.6523)$ (Table 3$)$.

Using Pearson correlation analysis, there was a positive significant correlation between serum NT-4 and severity of

Table I Clinical and laboratory data of the participants

\begin{tabular}{|c|c|c|c|c|c|}
\hline & $\begin{array}{l}\text { Group A } \\
n=60\end{array}$ & $\begin{array}{l}\text { Group B } \\
n=60\end{array}$ & $\begin{array}{l}\text { Group C } \\
n=60\end{array}$ & $\boldsymbol{F}$ & $P$-value \\
\hline Age (years) & $51 \pm 10$ & $46 \pm 17$ & $47 \pm 16$ & 1.95 & 0.1448 \\
\hline Sex (male/female) & $28 / 32$ & $29 / 31$ & $27 / 33$ & $\chi^{2}=0.134$ & 0.935 \\
\hline BMI $\left(\mathrm{kg} / \mathrm{m}^{2}\right)$ & $23.3 \pm 4.5$ & $22.4 \pm 5.1$ & $24.5 \pm 5.7$ & 2.54 & 0.082 \\
\hline Hemoglobin $(\mathrm{g} / \mathrm{dL})$ & $8.7 \pm 1.8$ & $8.9 \pm 1.7$ & $12.3 \pm 2.3$ & 64.52 & $<0.0001$ \\
\hline Calcium (md/dL) & $7.9 \pm 1.6$ & $7.3 \pm 1.9$ & $7.5 \pm 2.5$ & 1.35 & 0.261 \\
\hline Phosphors (mg/dL) & $5.9 \pm 1.6$ & $6.2 \pm 1.8$ & $6.3 \pm 1.7$ & 0.898 & 0.409 \\
\hline Parathyroid (pg/mL) & $498 \pm 333.6$ & $518 \pm 389.5$ & $51.4 \pm 12.6$ & 47.6 & $<0.0001$ \\
\hline Urea $(\mathrm{mg} / \mathrm{dL})$ & $164.7 \pm 47.9$ & $170.5 \pm 44.5$ & $24.6 \pm 12.4$ & 277.4 & $<0.0001$ \\
\hline Creatinine $(\mathrm{mg} / \mathrm{dL})$ & $6.4 \pm 2.9$ & $7.2 \pm 2.3$ & $0.3 \pm 0.5$ & 205.20 & $<0.0001$ \\
\hline NT-4 (pg/mL) & $7.32 \pm 4.2$ & $5.04 \pm 3.91$ & $3.07 \pm 2.65$ & 20.38 & 0.0001 \\
\hline \multirow[t]{3}{*}{$\mathrm{BDNF}(\mathrm{pg} / \mathrm{mL})$} & $3.29 \pm 3.11$ & $2.54 \pm 2.05$ & $1.9 \pm 1.6$ & 6.046 & 0.0029 \\
\hline & \multicolumn{2}{|c|}{ Group A vs Group C } & \multicolumn{2}{|c|}{ Group B vs Group C } & \\
\hline & $t$ & $P$-value & $t$ & $P$-value & \\
\hline NT-4 (pg/mL) & 6.63 & $<0.000 \mathrm{I}$ & 3.23 & 0.0016 & \\
\hline BDNF (pg/mL) & 3.079 & 0.0026 & 2.204 & 0.0294 & \\
\hline
\end{tabular}

Notes: Group A: uremic patients under regular hemodialysis with pruritus; Group B: uremic patients under regular hemodialysis without pruritus; Group C: normal controls. Comparison between the three groups was done by ANOVA test, while comparison between the two groups was done by simple statistical analysis $t$-test. $P \leq 0.05$ is significant, while $>0.05$ is nonsignificant.

Abbreviations: BDNF, brain-derived nerve growth factor; BMI, body mass index; NT-4, neurotrophin-4.

Table 2 Comparison between uremic patients with pruritus vs uremic patients without pruritus

\begin{tabular}{|l|l|l|l|l|}
\hline & Group A & Group B & t & P-value \\
\hline Age $($ years) & $5 I \pm 10$ & $46 \pm 17$ & 1.96 & 0.999 \\
\hline Sex $(\mathrm{male} / \mathrm{female})$ & $28 / 32$ & $29 / 31$ & $\chi^{2}=0.033$ & 0.855 \\
\hline BMI $\left(\mathrm{kg} / \mathrm{m}^{2}\right)$ & $23.3 \pm 4.5$ & $22.4 \pm 5.1$ & 1.025 & 0.83 \\
\hline Hemoglobin $(\mathrm{g} / \mathrm{dL})$ & $8.7 \pm 1.8$ & $8.9 \pm 1.7$ & 0.626 & 0.33 \\
\hline Calcium $(\mathrm{mg} / \mathrm{dL})$ & $7.9 \pm 1.6$ & $7.3 \pm 1.9$ & 1.871 & 0.905 \\
\hline Phosphors $(\mathrm{mg} / \mathrm{dL})$ & $5.9 \pm 1.6$ & $6.2 \pm 1.8$ & 0.965 & 0.816 \\
\hline Parathyroid $(\mathrm{pg} / \mathrm{mL})$ & $498 \pm 333.6$ & $518 \pm 389.5$ & 0.302 & 0.882 \\
\hline Urea $(\mathrm{mg} / \mathrm{dL})$ & $164.7 \pm 47.9$ & $170.5 \pm 44.5$ & 0.687 & 0.4933 \\
\hline Creatinine $(\mathrm{mg} / \mathrm{dL})$ & $6.4 \pm 2.9$ & $7.2 \pm 2.3$ & 1.674 & 0.0967 \\
\hline NT-4 $(\mathrm{pg} / \mathrm{mL})$ & $7.32 \pm 4.2$ & $5.04 \pm 3.9$ & 3.081 & 0.0026 \\
\hline BDNF $(\mathrm{pg} / \mathrm{mL})$ & $3.29 \pm 3.11$ & $2.54 \pm 2.05$ & 1.56 & 0.1215 \\
\hline Duration of hemodialysis (months) & $49 \pm 43$ & $41 \pm 35$ & 1.118 & 0.266 \\
\hline
\end{tabular}

Notes: Comparison between the two groups was by simple statistical analysis $t$-test. $P \leq 0.05$ is significant, while $>0.05$ is nonsignificant.

Abbreviations: BDNF, brain-derived nerve growth factor; BMI, body mass index; NT-4, neurotrophin-4.

Table 3 Serum level of NT-4 and BDNF according to the severity of pruritus by 5D score

\begin{tabular}{|l|l|l|l|l|l|}
\hline & $\begin{array}{l}\text { Moderate (5D score 10-15) } \\
\mathbf{n = 1 8}\end{array}$ & $\begin{array}{l}\text { Severe (5D score }>\text { 15-25) } \\
\mathbf{n}=\mathbf{1 9}\end{array}$ & $\begin{array}{l}\text { Very severe (>25) } \\
\mathbf{n = 2 3}\end{array}$ & $\boldsymbol{F}$ & $\boldsymbol{P}$-value \\
\hline NT-4 & $5.6 \pm 2.3$ & $6.2 \pm 4.9$ & $8.9 \pm 5.3$ & 3.257 & 0.0458 \\
\hline BDNF & $2.9 \pm 1.9$ & $3.2 \pm 2.7$ & $3.7 \pm 3.4$ & 0.4304 & 0.6523 \\
\hline
\end{tabular}

Notes: Comparison between the three groups was done by ANOVA test, while comparison of the two groups was by simple $t$-test. $P \leq 0.05$ is significant, while $>0.05$ is nonsignificant.

Abbreviations: BDNF, brain-derived nerve growth factor; NT-4, neurotrophin-4. 
Table 4 Correlations between severity of pruritus and different variables

\begin{tabular}{|l|l|l|}
\hline & $\boldsymbol{r}$ & $\boldsymbol{P}$-value \\
\hline Age & 0.175 & 0.528 \\
\hline Sex & 0.0191 & 0.33 \\
\hline Duration of hemodialysis & -0.122 & 0.64 \\
\hline BMl & -0.242 & 0.23 \\
\hline Hemoglobin & 0.016 & 0.932 \\
\hline Parathyroid & 0.024 & 0.897 \\
\hline Urea & 0.124 & 0.54 \\
\hline Creatinine & 0.085 & 0.683 \\
\hline Calcium & 0.163 & 0.754 \\
\hline Phosphorus & 0.287 & 0.239 \\
\hline NT-4 & 0.385 & 0.024 \\
\hline BDNF & 0.642 & 0.056 \\
\hline Notes: Pearson &
\end{tabular}

Notes: $r$, Pearson correlation coefficient. $P \leq 0.05$ is significant; $P>0.05$ is nonsignificant.

Abbreviations: BDNF, brain-derived nerve growth factor; BMI, body mass index; NT-4, neurotrophin-4. pruritus ( $r=0.385, P=0.024)$, while there were no significant correlations between severity of pruritus and other variables ( $r=0.642, P=0.056$ ) (Table 4; Figure 1).

\section{Discussion}

Pruritus is a common complaint and it has distressing impact on the uremic patients. ${ }^{11}$ Several hypothesis have emerged to explain etiopathogenesis of uremic pruritus that includes immunological, endocrinal, neurological and skin-mediated pathways. ${ }^{12}$

Neurotrophins are nerve growth and trophic factors including neurotrophin-3 (NT-3), NT-4/5, BDNF and nerve growth factor. ${ }^{13}$ Both NT-4 and BDNF share the same receptors, tyrosine kinase receptor trkB and the $\mathrm{p} 75$ neurotrophin receptor. ${ }^{14}$

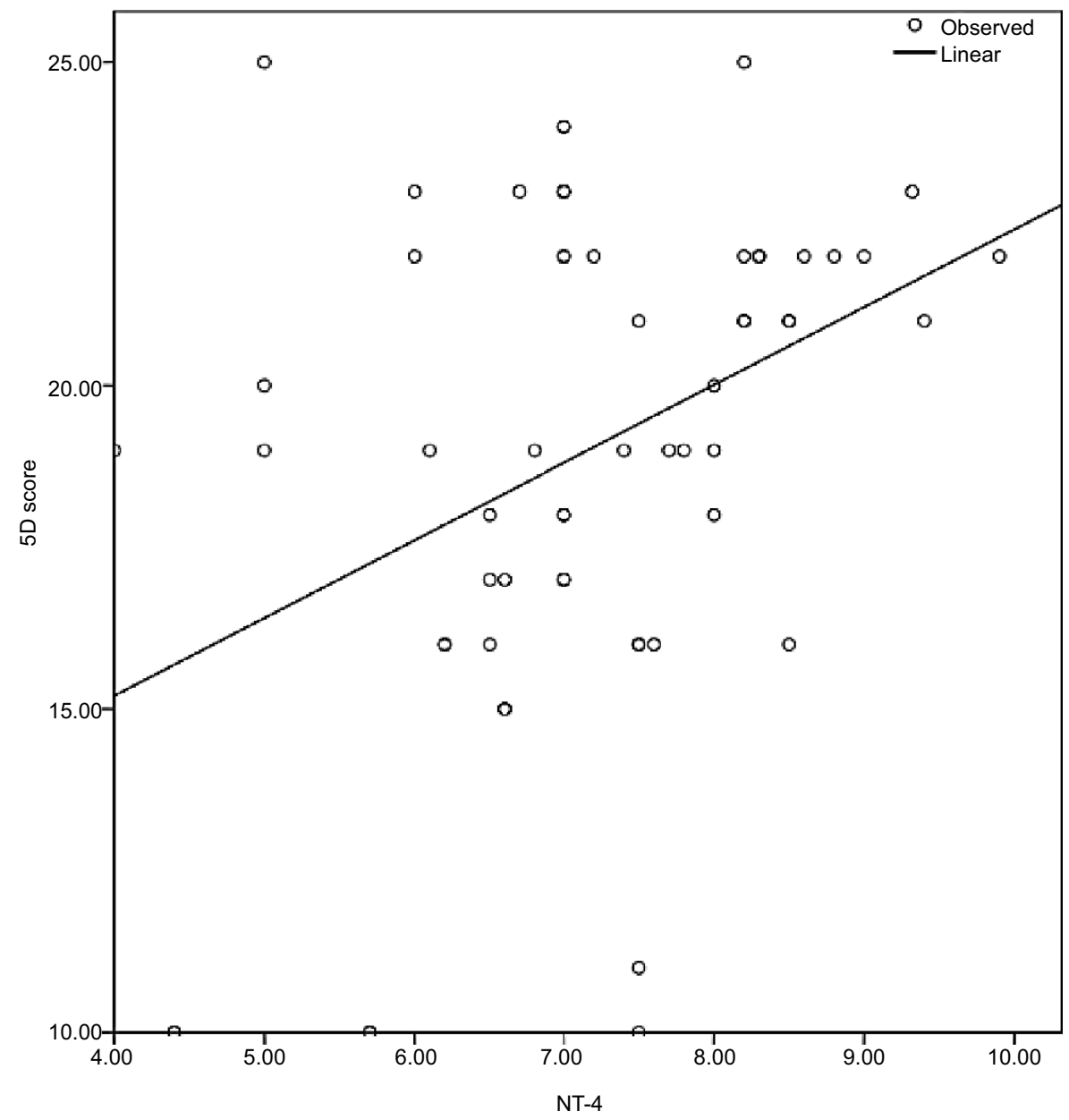

Figure I Correlation between 5D score and serum NT-4.

Abbreviation: NT-4, neurotrophin-4. 
Serum level of BDNF is varied in hemodialysis patients. Several studies showed it lower, ${ }^{15,16}$ equal, ${ }^{17}$ while others showed higher level than normal subjects. ${ }^{18}$

The exact BDNF source of origin in circulation is unknown, ${ }^{19}$ but BDNF can be found in the circulatory system, such as in serum and platelets. ${ }^{20,21}$ BDNF has the ability to cross blood-brain barrier, ${ }^{22}$ and its serum level can reflect CNS concentration. ${ }^{23}$

The current study showed that serum BDNF is elevated in uremic patients than control but not between uremic with pruritus vs nonpruritic patients. This elevation may facilitate the function of other factors that have roles in pruritus. Chronic pruritus may be due to defect in peripheral sensory pathway, cortical hypersensitivity, low cortical inhibitory mechanisms or noneffective spinal cord inhibitory mechanism. ${ }^{24} \mathrm{BDNF}$ has multiple effects on sensory nerves and CNS, which may facilitate its role in pruritus. BDNF, through its action on p75 neurotrophin the tropomyosin-related kinase (Trk) family of receptors, promotes axon elongation and branching of sensory neurons, ${ }^{25}$ synapse formation and stabilization, ${ }^{19}$ synaptic efficacy and synaptic plasticity ${ }^{26}$ This explains the cardinal role of BDNF in initiating and/or sustaining the hyperexcitability of the $\mathrm{CNS}^{27}{ }^{27}$ In addition, BDNF can induce state of allodynia, which facilitates pruritus. ${ }^{28}$ At dorsal root ganglion level, BDNF has a role in maintaining activation of the dorsal horn through NR2B-containing $N$-methyl D-aspartate receptors. ${ }^{29}$

Results of the present study showed an elevation of serum level of NT-4 in uremic patients with pruritus with direct significant correlation with severity of pruritus than both nonpruritic uremic patients and control participants. NT-4 is more potent than BDNF in neurological effects. ${ }^{30}$ This may explain its effect in uremic pruritus. Both NT-4 and BDNF are elevated in chronic itchy skin disease. ${ }^{31-34}$ However, serum level of BDNF is more affected by mood and cognitive function, which are common in uremic patients than NT-4. ${ }^{35,36}$ Although the BDNF is not significantly elevated in uremic patients with pruritus in this study; it may be due to low number of included patients. A further study on a larger number may be needed to rule out its role in uremic pruritus.

\section{Limitations}

Patients under peritoneal dialysis were not included in this study.

\section{Conclusion}

Serum level of NT-4 is elevated in uremic pruritus patients and may have a role on the hyperexcitability of nerves system in uremic pruritus.

\section{Author contributions}

All authors have contributed to 1) conception and design, analysis of data, and interpretation of data; 2) drafting the article, revising it critically for important intellectual content; 3) final approval of the version to be published; and 4) agreement to be accountable for all aspects of the work in ensuring that questions related to the accuracy or integrity of any part of the work are appropriately investigated and resolved.

\section{Disclosure}

The authors report no conflicts of interest in this work.

\section{References}

1. Mistik S, Utas S, Ferahbas A, et al. An epidemiology study of patients with uremic pruritus. J Eur Acad Dermatol Venereol. 2006;20(6): 672-678.

2. Kavurmacı M. Prevalence of uremic itching in patients undergoing hemodialysis. Hemodial Int. 2015;19(4):531-535.

3. Szepietowski JC, Balaskas E, Taube KM, Taberly A, Dupuy P; Uraemic Xerosis Working Group. Quality of life in patients with uraemic xerosis and pruritus. Acta Derm Venereol. 2011;91(3):313-317.

4. Shirazian S, Aina O, Park Y, et al. Chronic kidney disease-associated pruritus: impact on quality of life and current management challenges. Int J Nephrol Renovasc Dis. 2017;10:11-26.

5. Combs SA, Teixeira JP, Germain MJ. Pruritus in kidney disease. Semin Nephrol. 2015;35(4):383-391.

6. Raap U, Papakonstantinou E, Metz M, Lippert U, Schmelz M. Aktuelles zur kutanen Neurobiologie von Pruritus [Update on the cutaneous neurobiology of pruritus]. Hautarzt. 2016;67(8):595-600. German.

7. Manti S, Brown P, Perez MK, Piedimonte G. The role of neurotrophins in inflammation and allergy. Vitam Horm. 2017;104:313-341.

8. Elman S, Hynan LS, Gabriel V, Mayo MJ. The 5-D itch scale: a new measure of pruritus. Br J Dermatol. 2010;162(3):587-593.

9. Khan TM, Al-Haider I, Syed Sulaiman SA, Hassali MA. Linguistic validation of the $5 \mathrm{D}$ itching scale to Arabic in patients with end-stage kidney disease. J Ren Care. 2013;39(4):222-227.

10. Azim AA, Farag AS, El-Maleek Hassan DA, Abdu SM, Lashin SM, Abdelaziz NM. Role of interleukin-2 in uremic pruritus among attendants of AL-Zahraa hospital dialysis unit. Indian J Dermatol. 2015;60(2):211.

11. Weiss M, Mettang T, Tschulena U, Weisshaar E. Health-related quality of life in haemodialysis patients suffering from chronic itch: results from GEHIS (German Epidemiology Haemodialysis Itch Study). Qual Life Res. 2016;25(12):3097-3106.

12. Reszke R, Szepietowski JC. End-stage renal disease chronic itch and its management. Dermatol Clin. 2018;36(3):277-292.

13. Scuri M, Samsell L, Piedimonte G. The role of neurotrophins in inflammation and allergy. Inflamm Allergy Drug Targets. 2010;9(3):173-180.

14. Krimm RF, Davis BM, Noel T, Albers KM. Overexpression of neurotrophin 4 in skin enhances myelinated sensory endings but does not influence sensory neuron number. J Comp Neurol. 2006;498(4):455-465.

15. Zoladz JA, Śmigielski M, Majerczak J, et al. Hemodialysis decreases serum brain-derived neurotrophic factor concentration in humans. Neurochem Res. 2012;37(12):2715-2724.

16. Kielstein H, Suntharalingam M, Perthel R, et al. Role of the endogenous nitric oxide inhibitor asymmetric dimethylarginine (ADMA) and brainderived neurotrophic factor (BDNF) in depression and behavioural changes: clinical and preclinical data in chronic kidney disease. Nephrol Dial Transplant. 2015;30(10):1699-1705.

17. Wang LJ, Chen CK, Hsu HJ, Wu IW, Sun CY, Lee CC. Depression, 5HTTLPR and BDNF Val66Met polymorphisms, and plasma BDNF levels in hemodialysis patients with chronic renal failure. Neuropsychiatr Dis Treat. 2014;10:1235-1241. 
18. Shin SJ, Yoon HE, Chung S, Kim YG, Kim DJ. Plasma brainderived neurotrophic factor in hemodialysis patients. Int J Med Sci. 2012;9(9):772-777.

19. Zhen YF, Liu XY, Zhou DH, et al. Cognition, serum BDNF levels, and BDNF Val66Met polymorphism in type 2 diabetes patients and healthy controls. Oncotarget. 2018;9(3):3653-3662.

20. Pan W, Banks WA, Fasold MB, Bluth J, Kastin AJ. Transport of brainderived neurotrophic factor across the blood-brain barrier. Neuropharmacology. 1998;37(12):1553-1561.

21. Karege F, Schwald M, Cisse M. Postnatal developmental profile of brain-derived neurotrophic factor in rat brain and platelets. Neurosci Lett. 2002;328(3):261-264.

22. Palma-Álvarez RF, Ros-Cucurull E, Amaro-Hosey K, et al. Peripheral levels of BDNF and opiate-use disorder: literature review and update. Rev Neurosci. 2017;28(5):499-508.

23. Tekatas A, Arican O, Guler S, Aynac1 O, Dincer N. Pruritus: do A $\delta$ fibers play a role? J Dermatol. 2014;41(1):98-101.

24. Ji Y, Lu Y, Yang F, et al. Acute and gradual increases in BDNF concentration elicit distinct signaling and functions in neurons. Nat Neurosci. 2010;13(3):302-309.

25. Vicario-Abejón C, Owens D, McKay R, Segal M. Role of neurotrophins in central synapse formation and stabilization. Nat Rev Neurosci. 2002;3(12):965-974.

26. Park H, Poo MM. Neurotrophin regulation of neural circuit development and function. Nat Rev Neurosci. 2013;14(1):7-23.

27. Nijs J, Malfliet A, Ickmans K, Baert I, Meeus M. Treatment of central sensitization in patients with 'unexplained' chronic pain: an update. Expert Opin Pharmacother. 2014;15(12):1671-1683.

28. Vranken JH. Elucidation of pathophysiology and treatment of neuropathic pain. Cent Nerv Syst Agents Med Chem. 2012;12(4):304-314.
29. Geng SJ, Liao FF, Dang WH, et al. Contribution of the spinal cord BDNF to the development of neuropathic pain by activation of the NR2B-containing NMDA receptors in rats with spinal nerve ligation. Exp Neurol. 2010;222(2):256-266.

30. Runge EM, Hoshino N, Biehl MJ, Ton S, Rochlin MW. Neurotrophin-4 is more potent than brain-derived neurotrophic factor in promoting, attracting and suppressing geniculate ganglion neurite outgrowth. Dev Neurosci. 2012;34(5):389-401.

31. Grewe M, Vogelsang K, Ruzicka T, Stege H, Krutmann J. Neurotrophin-4 production by human epidermal keratinocytes: increased expression in atopic dermatitis. J Invest Dermatol. 2000;114(6):1108-1112.

32. Engelhart K, El Hindi T, Biesalski HK, Pfitzner I. In vitro reproduction of clinical hallmarks of eczematous dermatitis in organotypic skin models. Arch Dermatol Res. 2005;297(1):1-9.

33. Rössing K, Novak N, Mommert S, et al. Brain-derived neurotrophic factor is increased in serum and skin levels of patients with chronic spontaneous urticaria. Clin Exp Allergy. 2011;41(10): 1392-1399.

34. Raap U, Werfel T, Goltz C, et al. Circulating levels of brain-derived neurotrophic factor correlate with disease severity in the intrinsic type of atopic dermatitis. Allergy. 2006;61(12):1416-1418.

35. Teixeira AL, Barbosa IG, Diniz BS, Kummer A. Circulating levels of brain-derived neurotrophic factor: correlation with mood, cognition and motor function. Biomark Med. 2010;4(6):871-887.

36. Walz JC, Magalhães PV, Giglio LM, et al. Increased serum neurotrophin-4/5 levels in bipolar disorder. J Psychiatr Res. 2009;43(7): $721-723$.
Clinical, Cosmetic and Investigational Dermatology

\section{Publish your work in this journal}

Clinical, Cosmetic and Investigational Dermatology is an international, peer-reviewed, open access, online journal that focuses on the latest clinical and experimental research in all aspects of skin disease and cosmetic interventions. This journal is included on PubMed. The manuscript management system is completely online

\section{Dovepress}

and includes a very quick and fair peer-review system, which is all easy to use. Visit http://www.dovepress.com/testimonials.php to read real quotes from published authors 